\title{
Comparison of epidermal growth factor receptor tyrosine kinase inhibitors for patients with lung adenocarcinoma harboring different epidermal growth factor receptor mutation types
}

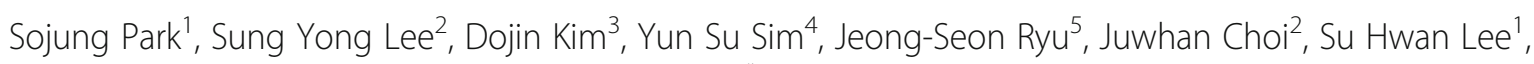
Yon Ju Ryu', Jin Hwa Lee ${ }^{1}$ and Jung Hyun Chang ${ }^{1 *}$

\begin{abstract}
Background: Epidermal growth factor receptor (EGFR) mutations in non-small-cell lung cancer predict sensitivity to EGFR tyrosine kinase inhibitors (TKIs). EGFR mutation types are associated with efficacy of EGFR TKIs. We investigated the clinical outcomes of afatinib, erlotinib, and gefitinib according to EGFR mutation type in patients with lung adenocarcinoma.

Methods: Between May 2010 and December 2018, we investigated 363 patients with advanced lung adenocarcinoma harboring EGFR mutations who received EGFR TKIs. Efficacies of EGFR TKIs such as response rate, progression-free survival (PFS), and overall survival (OS) were retrospectively evaluated according to exon 19 deletion (E19del), L858R point mutation (L858R) and uncommon mutations.
\end{abstract}

Results: The frequency of E19del was $48.2 \%$, that of L858R was $42.4 \%$, and that of uncommon mutations was $9.4 \%$. E19del and L858R were associated with superior PFS and OS compared with uncommon mutations. Erlotinib showed significantly inferior OS than other TKIs (30.8 \pm 3.3 in erlotinib vs. $39.1 \pm 4.3$ in afatinib vs. $48.4 \pm 6.3$ in gefitinib; $p=0.031$ ) in patients with L858R. Gefitinib showed significantly inferior PFS (4.6 \pm 1.1 in gefitinib vs. $11.6 \pm$ 2.7 in afatinib vs. $10.6 \pm 2.7$ in erlotinib; $p=0.049$ ) in patients with uncommon mutations.

Conclusion: Afatinib was significantly associated with a longer PFS, presenting constant effectiveness in all EGFR mutation types. Caution may be needed on the use of erlotinib for L858R and the use of gefitinib for uncommon EGFR mutations.

Keywords: Epidermal growth factor receptor, Non-small cell lung cancer, Adenocarcinoma, Survival, Tyrosine kinase inhibitor

\footnotetext{
*Correspondence: hs1017@ewha.ac.kr

1 Division of Pulmonary and Critical Care Medicine, College of Medicine, Ewha

Womans University, 1071 Anyangcheon-Ro, Yangcheon-gu, Seoul 07985,

Republic of Korea

Full list of author information is available at the end of the article
}

(c) The Author(s). 2020 Open Access This article is licensed under a Creative Commons Attribution 4.0 International License, which permits use, sharing, adaptation, distribution and reproduction in any medium or format, as long as you give appropriate credit to the original author(s) and the source, provide a link to the Creative Commons licence, and indicate if changes were made. The images or other third party material in this article are included in the article's Creative Commons licence, unless indicated otherwise in a credit line to the material. If material is not included in the article's Creative Commons licence and your intended use is not permitted by statutory regulation or exceeds the permitted use, you will need to obtain permission directly from the copyright holder. To view a copy of this licence, visit http://creativecommons.org/licenses/by/4.0/ The Creative Commons Public Domain Dedication waiver (http://creativecommons.org/publicdomain/zero/1.0/) applies to the data made available in this article, unless otherwise stated in a credit line to the data. 


\section{Background}

Somatic mutations in the epidermal growth factor receptor (EGFR) gene have been associated with sensitivity to EGFR tyrosine kinase inhibitors (TKIs) in non-small-cell lung cancer (NSCLC) [1-4]. EGFR mutations occur mainly in exons 18 through 21, which encompass most of the tyrosine kinase binding domain of EGFR. Previous studies demonstrated that exon 19 deletions (E19del) and L858R point mutation (L858R) are associated with better outcomes than uncommon EGFR mutations, such as G719X in exon 18 and exon 20 insertion [5-7]. For small case numbers and the highly heterogeneous spectrum of uncommon mutations, the efficacy of EGFR TKIs in patients with uncommon EGFR mutations has not been fully elucidated.

Afatinib, erlotinib, and gefitinib have been approved based on randomized trials showing superior progression-free survival (PFS), objective response rate (ORR), and more favorable safety profiles when compared with platinum-based chemotherapy in patients with EGFR-mutant NSCLC [1-4]. There are different mechanisms of action between the first-generation EGFR TKIs, which reversibly bind to and inhibit EGFR signaling, and the second-generation afatinib, which irreversibly blocks signaling from all relevant homo-dimers and hetero-dimers of the ErbB family of receptors [8]. However, there are no guidelines for the most appropriate choice of first-line treatment for a given patient because no prospective head-to-head comparison study has been conducted.

The aim of the present study was to investigate and compare the treatment efficacy of afatinib, erlotinib, and gefitinib according to EGFR mutation type in patients with lung adenocarcinoma.

\section{Methods}

\section{Study population}

We screened patients with advanced lung adenocarcinoma that harboured EGFR mutations from five secondary or tertiary medical institutes between May 2010 and December 2018. Of these, patients who received EGFR TKIs for at least 1 month and underwent disease status re-evaluation were included in the present study. Patients for whom treatment was discontinued for reasons other than disease progression, such as poor performance status, infection, transfer to another hospital, and dropout, were excluded. Demographic and clinicopathological information of patients were retrospectively reviewed through electronic medical records. The following variables were assessed: age, sex, body mass index (BMI), smoking history, EGFR mutation type, stage according to 8th TNM classification, treatment regimen, treatment response, PFS, overall survival (OS), and drug adverse events (AEs).
EGFR mutation types were classified as follows: E19del, L858R, and uncommon mutations that are defined as mutations other than E19del or L858R. Uncommon mutations also included concomitant mutation in two or more exons, therefore, concomitant mutation in E19del or L858R and in another exon was regarded as an uncommon mutation.

Informed consent was waived because of the retrospective study design, and the study was approved by the institutional review boards of all participating institutes. (Ewha Womans University: EUMC 2020-07-010002, Korean University: 2020GR0347, Soonchunhyang University: SCHBC2020-08-027, Hallym University: 2020-07-014, and Inha University: 2020-07-008).

\section{Evaluation of efficacy}

Each drug was orally administered once a day until progressive disease (PD) or unacceptable toxicity was noted. All patients were recommended to visit the clinic within 2 weeks after starting TKIs. If serious AEs were not noted at the first visit, patients visited the clinic every 4 or 8 weeks thereafter. Chest computed tomography (CT) was performed every 1 to 3 months to evaluate treatment response. ORR was calculated by checking the best response based on the Response Evaluation Criteria in Solid Tumors version 1.1 [9]. PFS was defined as the time from EGFR TKI commencement to either documented disease progression or death from any cause. OS was defined as the time from diagnosis to death. Drug AEs were graded according to the National Cancer Institute Common Terminology Criteria for Adverse Events (CTCAE) version 4.0 [10]. The date of data cutoff was December 31, 2019.

\section{Histology and molecular testing}

Tumor tissues were obtained by CT-guided needle biopsy, bronchoscopic biopsy, and surgical resection. DNA was extracted from archived paraffin-embedded tumor tissues. EGFR mutation testing was conducted in two ways according to the facilities and timing of each institution. Between 2010 and 2013, EGFR mutation status was analyzed by ISU ABXIS Co Ltd. (Seoul, Korea), an independent commercial laboratory. From 2013 to 2016, PNAClamp $^{\text {Tw }}$ EGFR Mutation Detection Kit with the PNA-mediated PCR clamping method (Panagene, Daejeon, Korea) was used at each institute to identify EGFR mutations in accordance with the manufacturer's instructions. The subtypes of detected mutations are described in Additional file 1.

\section{Statistical analysis}

Either Pearson chi-square test or Fisher's exact test was used to compare categorical variables, and a one-way analysis of variance test was used to compare continuous 
variables. PFS and OS curves were plotted using the Kaplan-Meier method and were compared using the logrank test. Variables selected by univariate analysis $(p<$ 0.1 ) were evaluated in a multivariate analysis using the Cox proportional hazard model. All tests of significance were two-sided, and differences among groups were considered significant when the $p$-value was $<0.05$. All statistical analyses were performed with SPSS software version 22.0 (IBM Corporation, Armonk, NY, USA).

\section{Results}

\section{Patient characteristics-}

From May 2010 to December 2018, a total of 410 patients with advanced NSCLC underwent mutation testing for EGFR and received EGFR TKIs. Excluding 47 patients who met the exclusion criteria, 363 patients with advanced lung adenocarcinoma were finally included in the present study (Fig. 1). The mean age was $67.6 \pm 11.0$ years; $62.3 \%$ were females (Table 1 ). The frequency of E19del was $48.2 \%$, that of L858R was $42.4 \%$, and that of uncommon mutations was $9.4 \%$. Of the 363 patients, $292(80.4 \%)$ received EGFR TKIs as first-line treatment, and $10(2.8 \%)$ received them as third-line treatment or beyond. No significant difference was found in treatment regimen among patients with each EGFR mutation type; afatinib was given to 102 (28.1\%) patients, erlotinib to 139 (38.3\%), and gefitinib to 122 $(33.6 \%, p=0.422)$.

\section{Objective response rate}

During a median follow-up duration of 24.9 months (range, 1.2-110.0 months), 209 patients (57.6\%) died and $63(17.4 \%)$ were still using EGFR TKIs at the time of data cutoff. The overall ORR and disease control rate (DCR) for EGFR TKIs was 73.3 and 93.1\%, respectively (Table 2). ORRs were 76.0, 76.0, and 47.1\% for E19del, L858R, and uncommon mutations, respectively $(p<$ 0.001). However, no significant differences were found in ORR according to EGFR TKI regimen. In patients harboring E19del and L858R, no significant difference was found in ORR (Table 3). In patients harboring uncommon mutations, DCRs were $81.8,88.9$, and $57.1 \%$ in afatinib-, erlotinib-, and gefitinib-treated patients, although they did not reach statistical significance thresholds $(p=0.182)$.

\section{Survival outcomes}

The median PFS of all patients was 12.1 months (95\% confidence interval [CI], 10.2-14.0). A significant difference was found in the median PFS among E19del, L858R, and uncommon mutations: 14.7 months (95\% CI, 12.6-16.8) for E19del, 10.9 months (95\% CI, 9.0-12.7) for L858R, and 5.0 months (95\% CI, 1.8-14.0) for uncommon mutations ( $p<0.001$; Fig. $2 \mathrm{a})$. The median OS of all patients was 33.4 months (95\% CI, 29.0-37.8) and a significant difference was found in the median OS among EGFR mutation types: 38.6 months $(95 \% \mathrm{CI}$, 32.9-44.3) for E19del, 28.6 months (95\% CI, 24.3-32.9) for L858R, and 22.8 months (95\% CI, 18.2-27.4) for uncommon mutations ( $p=0.001$; Fig. $2 \mathrm{~b}$ ).

The median PFS times for afatinib, erlotinib, and gefitinib were 17.0 months (95\% CI, 11.6-22.4), 11.2 months (95\% CI, 8.9-13.5), and 10.9 months (95\% CI, 8.3-13.5; $p=0.017$; Fig. 2c). However, no significant difference was found in OS according to EGFR TKI regimen (Fig. 2d).

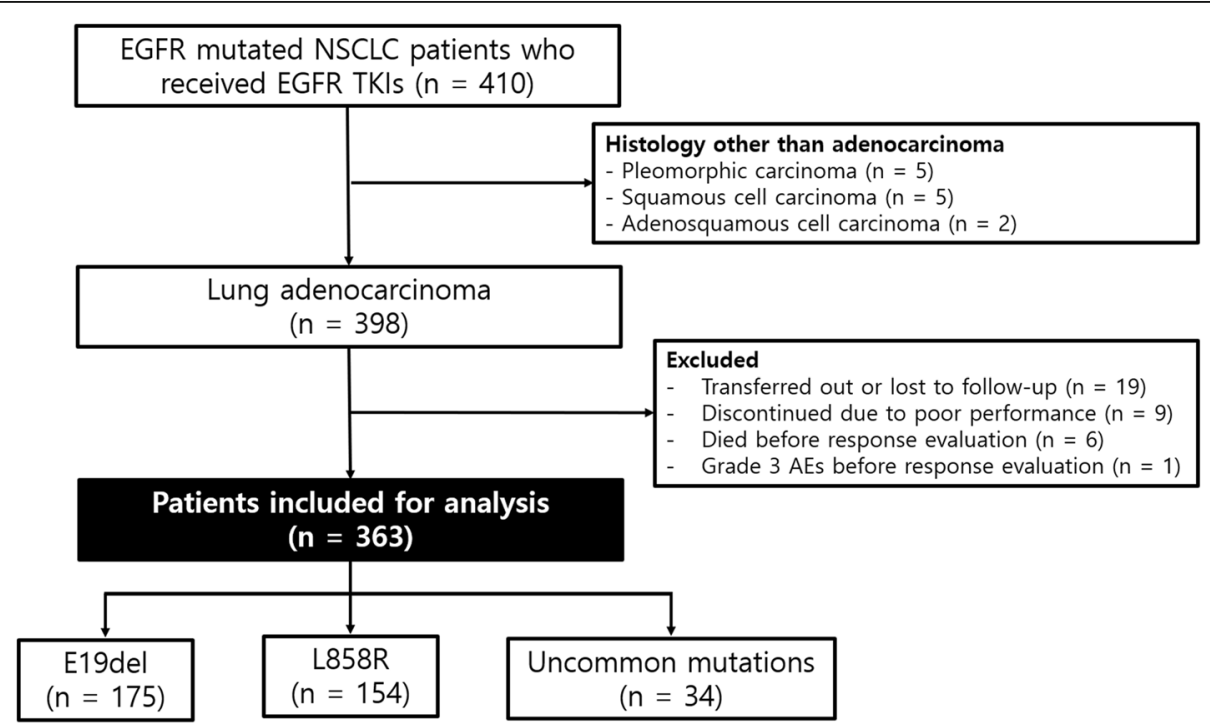

Fig. 1 Inclusion and exclusion criteria of patient enrolment. EGFR, epidermal growth factor receptor; NSCLC, non-small-cell lung cancer; TKIs, tyrosine kinase inhibitors; AEs, adverse events; E19del, exon 19 deletion; L858R, L858R point mutation; uncommon, uncommon mutations 
Table 1 Baseline characteristics of the study population

\begin{tabular}{|c|c|c|c|c|c|}
\hline & $\begin{array}{l}\text { Total } \\
(n=363)\end{array}$ & $\begin{array}{l}\text { E19del } \\
(n=175)\end{array}$ & $\begin{array}{l}\text { L858R } \\
(n=154)\end{array}$ & $\begin{array}{l}\text { Uncommon } \\
(n=34)\end{array}$ & $p$ value \\
\hline Age, mean \pm SD & $67.6 \pm 11.0$ & $66.5 \pm 11.8$ & $69.1 \pm 9.9$ & $66.1 \pm 10.8$ & 0.076 \\
\hline Sex, male & $137(37.7)$ & $68(38.9)$ & $59(38.3)$ & $10(29.4)$ & 0.572 \\
\hline $\mathrm{BMl}, \mathrm{kg} / \mathrm{m}^{2}$ & $24.0 \pm 3.5$ & $24.2 \pm 3.6$ & $23.6 \pm 3.3$ & $25.5 \pm 4.0$ & 0.012 \\
\hline Smoking status & & & & & 0.691 \\
\hline Never smoker & $258(71.3)$ & $123(70.3)$ & $109(71.2)$ & $26(76.5)$ & \\
\hline Ex-smoker & $76(21.0)$ & $36(20.6)$ & $35(22.9)$ & $5(14.7)$ & \\
\hline Current smoker & $28(7.7)$ & $16(9.1)$ & $9(5.9)$ & $3(8.8)$ & \\
\hline Stage & & & & & 0.361 \\
\hline Stage III & $31(8.5)$ & $15(8.6)$ & $11(7.1)$ & $5(14.7)$ & \\
\hline Stage IV & $332(91.5)$ & $160(91.4)$ & $143(92.9)$ & $29(85.3)$ & \\
\hline Previous chemotherapy & & & & & 0.442 \\
\hline 0 & $292(80.4)$ & $137(78.3)$ & $126(81.8)$ & $29(85.3)$ & \\
\hline 1 & $61(16.8)$ & $34(19.4)$ & $24(15.6)$ & $3(8.8)$ & \\
\hline$\geq 2$ & $10(2.8)$ & $4(2.3)$ & $4(2.6)$ & $2(5.9)$ & \\
\hline EGFR TKIs & & & & & 0.422 \\
\hline Afatinib & $102(28.1)$ & $53(30.3)$ & $38(24.7)$ & $11(32.4)$ & \\
\hline Erlotinib & $139(38.3)$ & $69(39.4)$ & $61(39.6)$ & $9(26.5)$ & \\
\hline Gefitinib & $122(33.6)$ & $53(30.3)$ & $55(35.7)$ & $14(41.2)$ & \\
\hline
\end{tabular}

Data are shown as $\mathrm{n}(\%)$ per each group, unless otherwise noted

E19del exon 19 deletion, L858R L858R point mutation, Uncommon uncommon mutations, SD standard deviation, BMI body mass index, EGFR epidermal growth factor receptor, $T K l$ tyrosine kinase inhibitor

In patients harboring E19del, no significant differences were found in PFS and OS according to EGFR TKI regimen (Fig. 3a and b). In patients harboring L858R mutation, the median PFS times for afatinib, erlotinib, and gefitinib were 12.1 months (95\% CI, 6.1-18.1), 9.2 months (95\% CI, 5.6-12.7), and 10.9 months (95\% CI, 7.8-13.9), respectively ( $p=0.068$; Fig. 3c). A significant

Table 2 Response rate of epidermal growth factor receptor tyrosine kinase inhibitors according to mutation type and treatment regimen

\begin{tabular}{llllll}
\hline & CR & PR & SD & PD & $p$ value \\
\hline Total $(n=363)$ & $1(0.3)$ & $265(73.0)$ & $72(19.8)$ & $25(6.9)$ & $<0.001$ \\
EGFR mutation types & & & & & \\
$\quad$ E19del $(n=175)$ & $1(0.6)$ & $132(75.4)$ & $33(18.9)$ & $9(5.1)$ & \\
L858R $(n=154)$ & 0 & $117(76.0)$ & $30(19.5)$ & $7(4.5)$ & \\
$\quad$ Uncommon $(n=34)$ & 0 & $16(47.1)$ & $9(26.5)$ & $9(26.5)$ & \\
EGFR TKIs & & & & & 0.914 \\
Afatinib $(n=102)$ & 0 & $74(72.5)$ & $21(20.6)$ & $7(6.9)$ & \\
Erlotinib $(n=139)$ & $1(0.7)$ & $100(71.9)$ & $29(20.9)$ & $9(6.5)$ & \\
Gefitinib $(n=122)$ & 0 & $91(74.6)$ & $22(18.0)$ & $9(7.4)$ & \\
\hline
\end{tabular}

Data are shown as $\mathrm{n}(\%)$ per each group

$C R$ complete response, $P R$ partial response, $S D$ stable disease, $P D$ progressive disease, E19del exon 19 deletion, L858R L858R point mutation, Uncommon uncommon mutations, EGFR epidermal growth factor receptor, TKIs tyrosine kinase inhibitors
Table 3 Response rate of epidermal growth factor receptor tyrosine kinase inhibitors according to mutation type

\begin{tabular}{llllll}
\hline & CR & PR & SD & PD & p value \\
\hline Total $(n=363)$ & $1(0.3)$ & $265(73.0)$ & $72(19.8)$ & $25(6.9)$ & \\
E19del $(n=175)$ & & & & & 0.785 \\
Afatinib $(n=53)$ & 0 & $38(71.7)$ & $12(22.6)$ & $3(5.7)$ & \\
Erlotinib $(n=69)$ & $1(1.4)$ & $54(78.3)$ & $10(14.5)$ & $4(5.8)$ & \\
Gefitinib $(n=53)$ & 0 & $40(75.5)$ & $11(20.8)$ & $2(3.8)$ & \\
L858R $(n=154)$ & & & & & 0.471 \\
Afatinib $(n=38)$ & 0 & $30(78.9)$ & $6(15.8)$ & $2(5.3)$ & \\
Erlotinib $(n=61)$ & 0 & $42(68.9)$ & $15(24.6)$ & $4(6.6)$ & \\
Gefitinib $(n=55)$ & 0 & $45(81.8)$ & $9(16.4)$ & $1(1.8)$ & \\
Uncommon $(n=34)$ & & & & & 0.332 \\
Afatinib $(n=11)$ & 0 & $6(54.5)$ & $3(27.3)$ & $2(18.2)$ & \\
Erlotinib $(n=9)$ & 0 & $4(44.4)$ & $4(44.4)$ & $1(11 . .1)$ & \\
Gefitinib $(n=14)$ & 0 & $6(42.9)$ & $2(14.3)$ & $6(42.9)$ & \\
\hline
\end{tabular}

Data are shown as $\mathrm{n}(\%)$ per each group

$C R$ complete response, $P R$ partial response, $S D$ stable disease, $P D$ progressive disease, E19del exon 19 deletion, L858R L858R point mutation, Uncommon uncommon mutations 
(A)

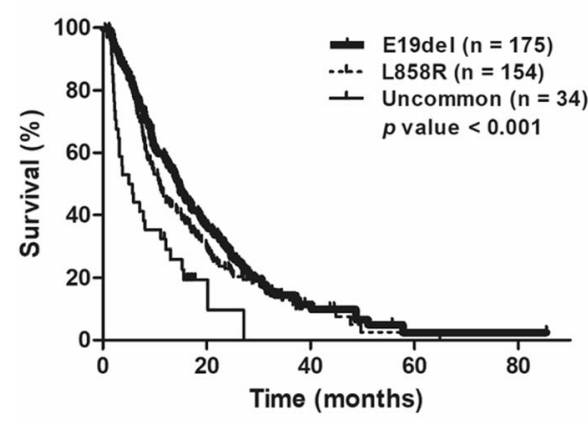

(C)

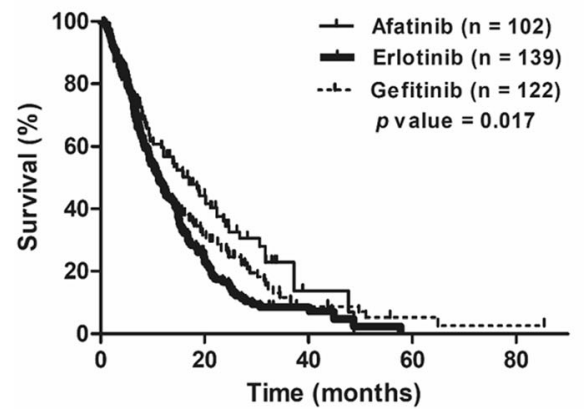

(B)

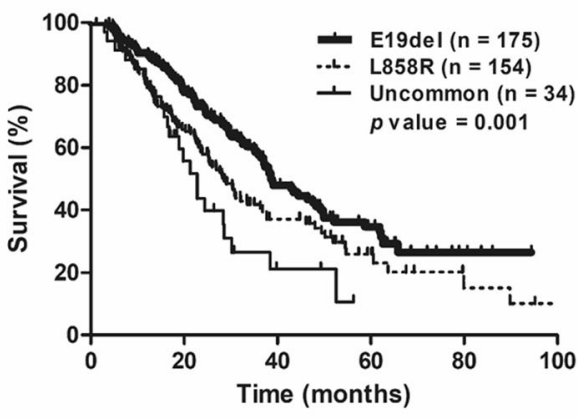

(D)

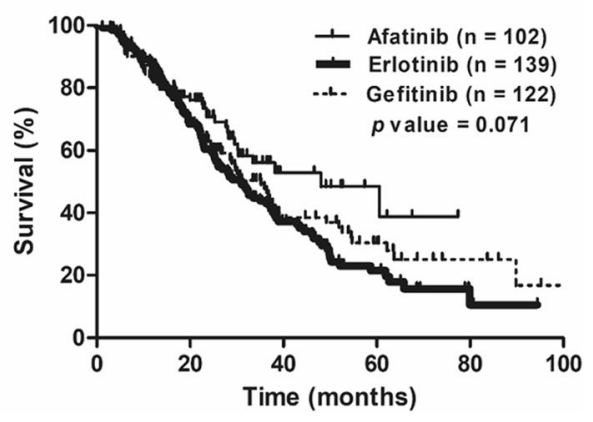

Fig. 2 Survival curves in lung adenocarcinoma patients harbouring EGFR mutations who received tyrosine kinase inhibitors. a Comparison of progression-free survival according to mutation type. $\mathbf{b}$ Comparison of overall survival according to mutation type. $\mathbf{c}$ Comparison of progressionfree survival according to treatment regimen. $\mathbf{d}$ Comparison of overall survival according to treatment regimen

difference was found in OS according to EGFR TKI regimen: 30.3 months $(95 \%$ CI, 10.0-50.6) in afatinib-, 23.1 months (95\% CI, 18.2-28.0) in erlotinib-, and 36.8 months (95\% CI, 12.3-61.3) in gefitinib-treated patients $(p=0.031$; Fig. 3d). In patients harboring uncommon mutations, a significant difference was found in the median PFS time according to EGFR TKI regimen: 12.1 months (95\% CI, 0.0-25.6) in afatinib-, 8.2 months (95\% CI, 7.0-9.5) in erlotinib-, and 3.0 months (95\% CI, 1.4$4.5)$ in gefitinib-treated patients ( $p=0.049$, Fig. 3e). No significant difference was found in OS according to EGFR TKI regimen in patients harboring uncommon mutations (Fig. 3f).

Univariate analysis revealed that BMI, smoking status, EGFR mutation type, type of EGFR TKI, and line of treatment were associated with PFS. In multivariate analysis, BMI (hazard ratio [HR], 0.963; 95\% CI, 0.9320.994; $p=0.021$ ) and EGFR mutation type (HR, 2.806; 95\% CI, $1.850-4.255 ; p<0.001)$ were associated with PFS (Additional file 2).

We evaluated isolated central nervous system (CNS) failure and bone failure without systemic disease progression during EGFR TKI treatment. No significant difference was found in the rate of isolated CNS failure among treatment regimen; however, patients who received erlotinib experienced significantly more isolated bone failure compared with those who received other regimens (18.7\% in erlotinib versus 9.8\% in afatinib and $9.0 \%$ in gefitinib, respectively, $p=$ 0.036).

\section{Serious adverse events}

We evaluated the incidence of serious AEs which were defined as CTCAE grades 3 to 5 . The overall incidence of serious AEs was 7.4\% (Additional file 3). The most common AEs were skin rash (5.0\%), followed by gastrointestinal toxicity $(2.2 \%)$ and myalgia $(0.3 \%)$. The incidence of serious AEs was comparable among the three treatment groups. No treatment-related deaths occurred for all three drugs.

\section{Acquired mutation after use of EGFR TKIs}

Among 300 patients who discontinued EGFR TKIs at the time of data cutoff, 101 patients (33.7\%) underwent re-biopsy for investigation of acquired resistance mutations. As a result, 50 cases (49.5\%) acquired T790M mutation and one case transformed to small-cell lung cancer. Three cases (4.0\%) were converted to EGFR wild-type (Table 4). No difference was found in the rate of acquired resistance mutations according to initial EGFR mutation type and treatment regimen. 

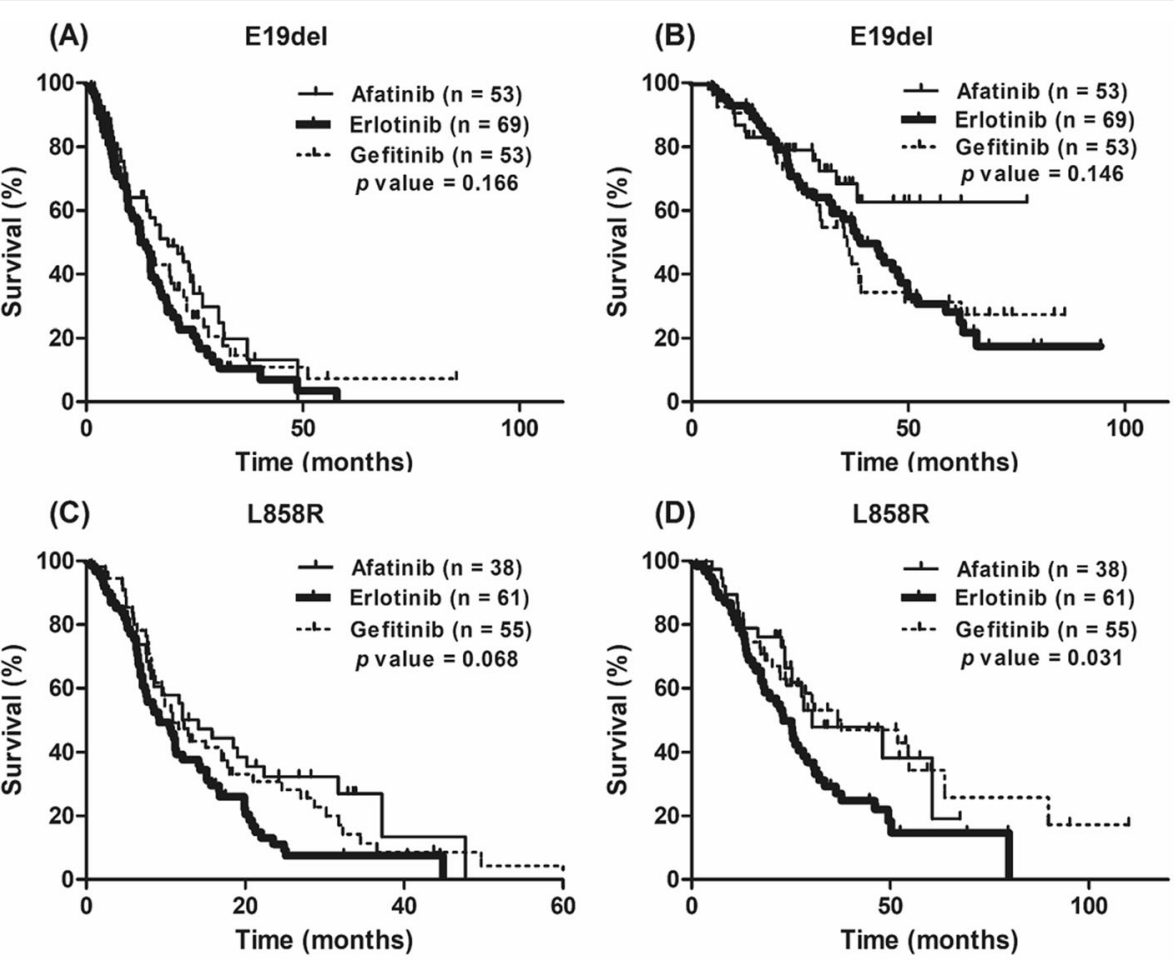

(E)

Uncommon mutations
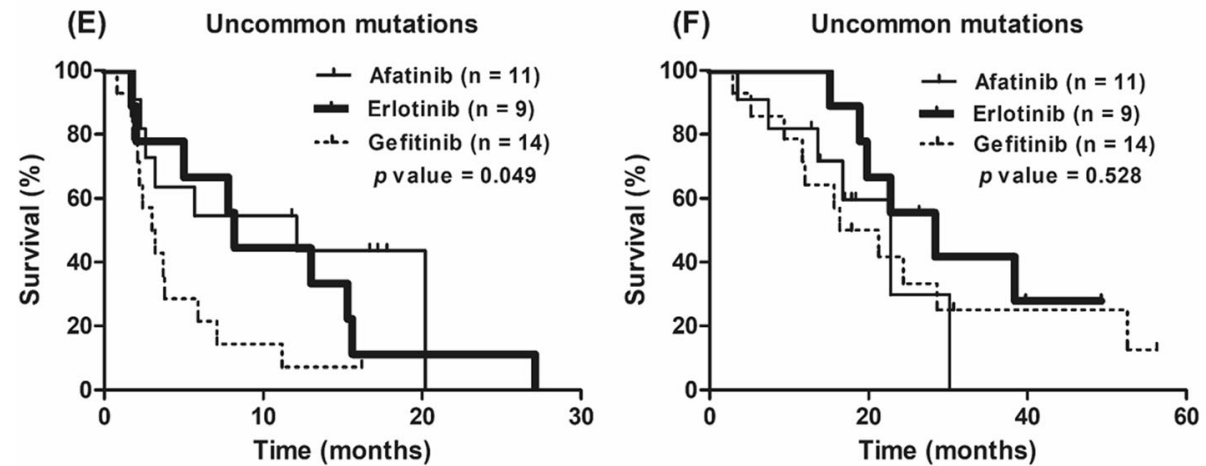

Fig. 3 Survival curves in lung adenocarcinoma patients harbouring EGFR mutations according to each mutation type. a, b Comparison of progression-free survival and overall survival for exon 19 deletion. c, d Comparison of progression-free survival and overall survival for L858R point mutation. $\mathbf{e}, \mathbf{f}$ Comparison of progression-free survival and overall survival for uncommon mutations

\section{Discussion}

Afatinib, erlotinib, and gefitinib are recommended for the first-line treatment of NSCLC harboring EGFR mutations. Although these three drugs have all been used, the optimal choice for each patient is uncertain, as comparative studies have been scarce. The present study demonstrated that significantly different OS were found among EGFR TKIs in patients with L858R, as well as varying PFS in those with uncommon EGFR mutations, although multivariate analysis showed that a certain TKI regimen was not associated with superior PFS in a particular EGFR mutation type.

The WJOG $5108 \mathrm{~L}$ study which compared gefitinib with erlotinib demonstrated that no significant difference was found in PFS between the two TKIs [11]. The
LUX-Lung 7 trial which compared afatinib with gefitinib demonstrated that afatinib showed a superior PFS compared with gefitinib [12]. However, this survival gain was not identified when it was analyzed separately for E19del and L858R. The present study showed that patients with L858R who received erlotinib had a tendency to experience a shortened PFS compared with those who received other regimens, and patients with uncommon mutations who received gefitinib had a shorter PFS compared with those who received other regimens. However, afatinib showed consistent effectiveness for all EGFR mutation types without a significantly increased risk of serious AEs. We assumed that this constant effectiveness might have caused superior PFS of afatinib in the total study population but not in a certain EGFR mutation type. 
Table 4 Acquired resistance mechanism after the use of epidermal growth factor receptor tyrosine kinase inhibitors according to mutation type and treatment regimen

\begin{tabular}{|c|c|c|c|c|c|}
\hline & No change & T790M & SCLC & Wild-type & $p$ value \\
\hline Total $(n=101)$ & $46(45.5)$ & $50(49.5)$ & $1(1.0)$ & $4(4.0)$ & \\
\hline \multicolumn{6}{|l|}{ EGFR mutation types } \\
\hline E19del $(n=51)$ & $21(41.2)$ & $27(52.9)$ & 0 & $3(5.9)$ & 0.447 \\
\hline $\operatorname{L858R}(n=42)$ & $19(45.2)$ & $21(50.0)$ & $1(2.4)$ & $1(2.4)$ & 0.601 \\
\hline Uncommon $(n=8)$ & $6(75.0)$ & $2(25.0)$ & 0 & 0 & 0.371 \\
\hline \multicolumn{6}{|l|}{ EGFR TKIs } \\
\hline Afatinib $(n=38)$ & $21(55.3)$ & $14(36.8)$ & 0 & $3(7.9)$ & 0.130 \\
\hline Erlotinib $(n=32)$ & $12(37.5)$ & $19(59.4)$ & $1(3.1)$ & 0 & 0.168 \\
\hline Gefitinib $(n=31)$ & $13(41.9)$ & $17(54.8)$ & 0 & $1(3.2)$ & 0.747 \\
\hline
\end{tabular}

A total of 101 patients underwent re-biopsy for investigation of acquired resistance after discontinuation of EGFR TKI. The most common mechanism was acquisition of T790M mutation, followed by conversion to EGFR wild-type, and transformation to small-cell lung cancer. No difference was found in the rate of acquired resistance mutations according to initial EGFR mutation type and treatment regimen

Data are shown as $\mathrm{n}(\%)$ per each group

SCLC small-cell lung cancer, E19del exon 19 deletion, L858R L858R point mutation, Uncommon uncommon mutations

The WJOG $5108 \mathrm{~L}$ study showed that the HR was in favor of gefitinib for L858R mutation, and erlotinib for uncommon mutations, although they did not reach statistical significance. Additionally, Kim et al. showed a similar tendency for PFS, although they also could not reach the statistical threshold [13]. Therefore, a large, randomized prospective study is needed to confirm that there are differences in the treatment efficacy of the three EGFR TKIs according to EGFR mutation type.

The incidence of uncommon mutations was $9.4 \%$ in the present study. The low prevalence and high heterogeneity make the comprehensive evaluation of the treatment effectiveness of EGFR TKIs for uncommon EGFR mutations difficult. EGFR exon 20 insertions and de novo T790M mutations are considered resistance mutations [14-16]. However, G719X, S768I, and L861Q may be sensitizing mutations [14, 17-19]. A combined posthoc analysis of the LUX-Lung 2, 3, and 6 trials demonstrated that afatinib showed a median PFS of 10.7 months for point mutations and duplications in exons 18-21, 2.9 months for de novo T790M mutations, and 2.7 months for exon 20 insertions [18]. Tu et al. demonstrated that patients with compound L858R or G719X who received first-generation EGFR TKIs showed a comparable PFS with classical EGFR mutations, whereas those with T790M mutation or exon 20 insertion showed median PFS rates of 1.0 and 3.0 months, respectively [20]. Previous studies could not show a definite survival benefit of afatinib but a tendency for improved PFS and ORR compared with first-generation EGFR TKIs [21, 22]. We found that afatinib showed comparable efficacy with erlotinib in uncommon mutations. Therefore, afatinib or erlotinib may be recommended for first-line treatment in patients harboring uncommon EGFR mutations.
The incidence of serious AEs was lower than in previous studies [3, 4, 11]. This finding could be related to the limitation of retrospective studies, which might have omitted such cases. However, we took serious AEs that required medical intervention into account without mild AEs, and thus the possibility of omitting serious cases might be small. We assumed that appropriate dose reduction with or without temporary interruption, best supportive care, and racial differences might cause a low incidence of serious AEs.

The present study has several limitations. First, it is a retrospective observational study. The choice of EGFR TKI was based on the physician's clinical judgment or preference, which might result in a selection bias. Second, the uncommon mutation cohort was relatively small and highly heterogeneous, which made subgroup analyses difficult. Additionally, the large number of patients with E19del subtype was unspecified and the minor type of E19del might be misclassified to E19del [23]. Third, only $33.7 \%$ of patients underwent re-biopsy to examine the resistance mechanism, which might cause selection bias and reduce the reliability of the result for the acquired resistance mechanism according to EGFR TKI or EGFR mutation type. Additionally, nextgeneration sequencing was not routinely performed, so there might be missed resistance mechanisms such as $M E T$ amplification and BRAF mutation. Further experimental approach to investigate the resistance mechanism according to EGFR mutation type and treatment regimen is needed. Lastly, National Comprehensive Cancer Network guideline recommends osimertinib as a preferred first line regimen in patients with EGFR-mutant NSCLC since version 1.2019 [24]. The present study was conducted with patients who had received EGFR TKI during May 2010 and December 2018, therefore, no 
patients had received osimertinib as a first line treatment. In addition, osimertinib is not yet covered by national insurance as first line treatment in Korea and many EGFR-mutant patients cannot afford the expense. Therefore, afatinib, erlotinib, and gefitinib still need to be selected as a first-line therapy in many cases. Indeed, 37 patients received osimertinib after acquiring T790M mutation.

\section{Conclusions}

Afatinib was significantly associated with a longer PFS, presenting constant effectiveness in all EGFR mutation types, although multivariate analysis showed that a specific TKI regimen was not associated with superior PFS in a particular EGFR mutation type. However, caution may be needed on the use of erlotinib for L858R and the use of gefitinib for uncommon EGFR mutations.

\section{Supplementary Information}

The online version contains supplementary material available at https://doi. org/10.1186/s12885-020-07765-6.

\section{Additional file $\mathbf{1}$ Table $\mathbf{S 1}$. EGFR mutation subtypes.}

Additional file $\mathbf{2}$ Table S2. Univariate and multivariate Cox proportional hazard analysis for progression-free survival in patients harboring epidermal growth factor receptor mutation and received tyrosine kinase inhibitors.

Additional file $\mathbf{3}$ Table S3. Drug-related serious adverse events.

\section{Abbreviations}

EGFR: Epidermal growth factor receptor; TKIs: Tyrosine kinase inhibitors; NSCL C: Non-small-cell lung cancer; E19del: Exon 19 deletions; L858R: L858R point mutation; PFS: Progression-free survival; ORR: Objective response rate; BMI: Body mass index; OS: Overall survival; AEs: Adverse events; PD: Progressive disease; CT: Computed tomography; CTCAE: Common Terminology Criteria for Adverse Events; DCR: Disease control rate; Cl: Confidence interval; HR: Hazard ratio; CNS: Central nervous system

\section{Acknowledgements}

Not applicable.

\section{Authors' contributions}

SP and JHC had full access to all of the data in the study and takes responsibility for the integrity of the data and the accuracy of the data analysis. JHC contributed to the design of the study. SYL, DK, YSS, J-SR, JC, SHL, YJR, JHL, and JHC contributed to subject recruitment. SP contributed data analysis and drafting. All authors read and approved the final manuscript.

\section{Funding \\ None.}

\section{Availability of data and materials}

The datasets used and/or analysed during the current study available from the corresponding author on reasonable request.

\section{Ethics approval and consent to participate}

Informed consent was waived because of the retrospective study design, and the study was approved by the institutional review boards of all participating institutes. (Ewha Womans University: EUMC 2020-07-010-002, Korean University: 2020GR0347, Soonchunhyang University: SCHBC2020-08027, Hallym University: 2020-07-014, and Inha University: 2020-07-008).
Consent for publication

Not applicable.

\section{Competing interests}

The authors declare that they have no competing interests.

\section{Author details}

${ }^{1}$ Division of Pulmonary and Critical Care Medicine, College of Medicine, Ewha Womans University, 1071 Anyangcheon-Ro, Yangcheon-gu, Seoul 07985, Republic of Korea. ${ }^{2}$ Division of Respiratory, Allergy and Critical Care Medicine, Department of Internal Medicine, Korea University Guro Hospital, Seoul, Republic of Korea. ${ }^{3}$ Division of Allergy and Respiratory Medicine, Soonchunhyang University Bucheon Hospital, Bucheon, Gyeonggi, Republic of Korea. ${ }^{4}$ Division of Pulmonary, Allergy and Critical Care Medicine, Department of Internal Medicine, Hallym University Kangnam Sacred Heart Hospital, Seoul, Republic of Korea. ${ }^{5}$ Department of Internal Medicine, Inha University College of Medicine, Incheon, Republic of Korea.

Received: 28 September 2020 Accepted: 23 December 2020

Published online: 11 January 2021

\section{References}

1. Mok TS, Wu Y-L, Thongprasert S, Yang C-H, Chu D-T, Saijo N, et al. Gefitinib or carboplatin-paclitaxel in pulmonary adenocarcinoma. N Engl J Med. 2009:361:947-57.

2. Zhou C, Wu Y-L, Chen G, Feng J, Liu X-Q, Wang C, et al. Erlotinib versus chemotherapy as first-line treatment for patients with advanced EGFR mutation-positive non-small-cell lung cancer (OPTIMAL, CTONG-0802): a multicentre, open-label, randomised, phase 3 study. Lancet Oncol. 2011;12: 735-42.

3. Sequist LV, Yang JC, Yamamoto N, O'Byrne K, Hirsh V, Mok T, et al. Phase III study of afatinib or cisplatin plus pemetrexed in patients with metastatic lung adenocarcinoma with EGFR mutations. J Clin Oncol. 2013;31:3327-34.

4. Wu Y-L, Zhou C, Hu C-P, Feng J, Lu S, Huang Y, et al. Afatinib versus cisplatin plus gemcitabine for first-line treatment of Asian patients with advanced non-small-cell lung cancer harbouring EGFR mutations (LUX-lung 6): an open-label, randomised phase 3 trial. Lancet Oncol. 2014;15:213-22.

5. Beau-Faller M, Prim N, Ruppert A-M, Nanni-Metéllus I, Lacave R, Lacroix L, et al. Rare EGFR exon 18 and exon 20 mutations in non-small-cell lung cancer on 10117 patients: a multicentre observational study by the French ERMETIC-IFCT network. Ann Oncol. 2014;25:126-31.

6. De Pas T, Toffalorio F, Manzotti M, Fumagalli C, Spitaleri G, Catania C, et al Activity of epidermal growth factor receptor-tyrosine kinase inhibitors in patients with non-small cell lung cancer harboring rare epidermal growth factor receptor mutations. J Thorac Oncol. 2011;6:1895-901.

7. Watanabe S, Minegishi Y, Yoshizawa H, Maemondo M, Inoue A, Sugawara S, et al. Effectiveness of gefitinib against non-small-cell lung cancer with the uncommon EGFR mutations G719X and L861Q. J Thorac Oncol. 2014;9:18994.

8. Solca F, Dahl G, Zoephel A, Bader G, Sanderson M, Klein C, et al. Target binding properties and cellular activity of afatinib (BIBW2992), an irreversible ErbB family blocker. J Pharmacol Exp Ther. 2012;343:342-50.

9. Eisenhauer EA, Therasse P, Bogaerts J, Schwartz LH, Sargent D, Ford R, et al. New response evaluation criteria in solid tumours: revised RECIST guideline (version 1.1). Eur J Cancer. 2009:45:228-47.

10. National Cancer Institute Common terminology criteria for adverse events (CTCAE), Version 4.0. https://ctep.cancer.gov/protocolDevelopment/ electronic_applications/ctc. htm. Accessed June 2020.

11. Urata Y, Katakami N, Morita S, Kaji R, Yoshioka H, Seto T, et al. Randomized phase III study comparing gefitinib with erlotinib in patients with previously treated advanced lung adenocarcinoma: WJOG 5108L. J Clin Oncol. 2016;34: 3248-57.

12. Park K, Tan E-H, O'Byrne K, Zhang L, Boyer M, Mok T, et al. Afatinib versus gefitinib as first-line treatment of patients with EGFR mutation-positive nonsmall-cell lung cancer (LUX-lung 7): a phase 2B, open-label, randomised controlled trial. Lancet Oncol. 2016:17:577-89.

13. Kim Y, Lee S-H, Ahn JS, Ahn M-J, Park K, Sun J-M. Efficacy and safety of afatinib for EGFR-mutant non-small cell lung cancer, compared with gefitinib or erlotinib. Cancer Res Treat. 2019;51:502-9.

14. Yasuda H, Park E, Yun C-H, Sng NJ, Lucena-Araujo AR, Yeo W-L, et al. Structural, biochemical, and clinical characterization of epidermal growth 
factor receptor (EGFR) exon 20 insertion mutations in lung cancer. Sci Transl Med. 2013;5:216ra177.

15. Naidoo J, Sima CS, Rodriguez K, Busby N, Nafa K, Ladanyi M, et al. Epidermal growth factor receptor exon 20 insertions in advanced lung

adenocarcinomas: clinical outcomes and response to erlotinib. Cancer. 2015; 121:3212-20.

16. Yu HA, Arcila ME, Hellmann MD, Kris MG, Ladanyi M, Riely GJ. Poor response to erlotinib in patients with tumors containing baseline EGFR T790M mutations found by routine clinical molecular testing. Ann Oncol. 2014;25: 423-8.

17. Castellanos E, Feld E, Horn L. Driven by mutations: the predictive value of mutation subtype in EGFR-mutated non-small cell lung cancer. J Thorac Oncol. 2017;12:612-23.

18. Yang JC, Sequist LV, Geater SL, Tsai C-M, Mok TSK, Schuler M, et al. Clinical activity of afatinib in patients with advanced non-small-cell lung cancer harbouring uncommon EGFR mutations: a combined post-hoc analysis of LUX-lung 2, LUX-lung 3, and LUX-lung 6. Lancet Oncol. 2015;16:830-8.

19. Chiu C-H, Yang C-T, Shih J-Y, Huang M-S, Su W-C, Lai R-S, et al. Epidermal growth factor receptor tyrosine kinase inhibitor treatment response in advanced lung adenocarcinomas with G719X/L861Q/S768I mutations. J Thorac Oncol. 2015;10:793-9.

20. Tu H-Y, Ke E-E, Yang J-J, Sun Y-L, Yan H-H, Zheng M-Y, et al. A comprehensive review of uncommon EGFR mutations in patients with nonsmall cell lung cancer. Lung Cancer. 2017;114:96-102.

21. Shen $Y-C$, Tseng $G-C$, Tu C-Y, Chen W-C, Liao W-C, Chen W-C, et al. Comparing the effects of afatinib with gefitinib or Erlotinib in patients with advanced-stage lung adenocarcinoma harboring non-classical epidermal growth factor receptor mutations. Lung Cancer. 2017;110:56-62.

22. Chang L-C, Lim C-K, Chang L-Y, Chen K-Y, Shih J-Y, Yu C-J. Non-small cell lung cancer harbouring non-resistant uncommon EGFR mutations: mutation patterns, effectiveness of epidermal growth factor receptor-tyrosine kinase inhibitors and prognostic factors. Eur J Cancer. 2019;1 19:77-86.

23. Xu H, Li W, Yang G, Li J, Yang L, Xu F, et al. Heterogeneous response to first-generation tyrosine kinase inhibitors in non-small-cell lung cancers with different EGFR exon 19 mutations. Target Oncol. 2020;15:357-64.

24. National Comprehensive Cancer Network (NCCN). NCCN clinical practice guidelines in oncology. Non-Small Cell Lung Cancer. Version 8. 2020, Available at: https://www.nccn.org/professionals/physician_gls/ Accessed Nov 2020

\section{Publisher's Note}

Springer Nature remains neutral with regard to jurisdictional claims in published maps and institutional affiliations.

Ready to submit your research? Choose BMC and benefit from:

- fast, convenient online submission

- thorough peer review by experienced researchers in your field

- rapid publication on acceptance

- support for research data, including large and complex data types

- gold Open Access which fosters wider collaboration and increased citations

- maximum visibility for your research: over $100 \mathrm{M}$ website views per year

At $\mathrm{BMC}$, research is always in progress.

Learn more biomedcentral.com/submissions 